\title{
Research on Constructing the English Teaching Mode Based on TOPCARES-CDIO and OBE
}

\author{
Chuan ZHOU \\ School of Foreign Languages \\ Dalian Neusoft University of Information \\ Gan Jingzi District, Dalian, P.R. China \\ zhouchuan@neusoft.edu.cn
}

\begin{abstract}
This paper is to construct an English teaching mode where the learners will be learning via projects in the simulated workplace, based on the school-based innovative TOPCARES-CDIO and OBE educational teaching concept and talent cultivation mode. By introducing the overall design, concrete implementation and assessment of the learners' performance and project deliverables, this paper illustrates that this teaching mode combined with workplace application and flipped classroom can not only stimulate the students' enthusiasm to participate in the learning process, but also train the students' language practical ability in the simulated working environment and the spirit of teamwork. In conclusion, the set objectives of education are all well achieved.
\end{abstract}

Keywords-TOPCARES-CDIO; OBE; project-based teaching; workplace application

\section{INTRODUCTION OF THE TOPCARES-CDIO TALENT TRAINING MODE}

First of all, CDIO engineering education mode is the latest achievement of international engineering education reform in recent years. Since 2000, four universities, including the Massachusetts Institute of Technology and the Royal Swedish Institute of Technology, have established the CDIO engineering education mode after four years of exploration and research. C stands for conceive, D for Design, I for Implementation, $\mathrm{O}$ for Operate, and is a concentrated generalization and abstract expression of "learning by doing" and "Project-Based Education and Learning" (PBL). [1] The CDIO education mode emphasizes "student-centered" and projects are used to reflect the course content, cultivate students' active learning and practical ability, cultivate students' ability to analyze and solve problems, and finally meet the requirements of enterprises for professional and technical talents.

TOPCARES-CDIO application-oriented talent training mode and capability index system are formed, constructed and implemented on the basis of learning from the CDIO engineering education concept and combining with the practice of IT application-oriented talent training. TOPCARES-CDIO project is divided into five levels: Level 1 project (cornerstone project and capstone project) is a comprehensive project that includes the core courses and ability requirements of the major, focusing on the cultivation of students' core professional competence. Level 2 project (course group project) refers to the course group project based on multiple courses and includes a set of related core course competency requirements. Level 3 project (course project) refers to the course project set within a single course to enhance the realization of the course capability goal. Level 4 project (unit group project) refers to the unit group project designed for the purpose of strengthening the course capability based on the ability requirements of more than two units (modules) of one course. Level 5 project (unit project) is a unit project based on a unit (module) of a course designed to enhance ability cultivation. [2]

\section{THEORETICAL BASIS}

The theoretical basis of construction based on the work settings is Constructivism. Constructivist learning view and situational learning theory hold that the acquisition of knowledge and the cultivation of ability are constructed in the process of the interaction between individual learners and their simulated workplace, instead of the objective definition or subjective creation (Young 1993). Therefore, to make students obtain knowledge of English needed in the future career and professional competence, a brand new English teaching mode has to be built in the learning process so that the students in the relatively real environment has the chance to learn the language knowledge, find and solve problems creatively in practice, improve their language ability, and realizing the maximization of personal value and ability in language learning. Therefore, constructivism and situational learning theory provide a strong theoretical basis and guidance for project-based teaching design.

Outcome-based education (OBE) is an educational theory that bases each part of an educational system around goals (outcomes). By the end of the educational experience, each student should have achieved the goal. There is no single specified style of teaching or assessment in OBE; instead, classes, opportunities, and assessments should all help students achieve the specified outcomes. The role of the faculty adapts into instructor, trainer, facilitator, and/or mentor based on the outcomes targeted.

As a supplement to the teaching mode, the strategy of flipped classroom is also applied. A flipped classroom is a type of blended learning that transforms the traditional learning mode by uploading most of the teaching content outside of the classroom. It moves some teaching content that is traditionally dealt with in the classroom to outside the classroom. Before 
come into the classroom, the students have to learn and digest the online learning resources of all forms by themselves. While in a classroom, the students are engaged in solving the problems or confusions with the guidance of a mentor.

The flipped classroom intends to be placed under a learner-centered model in which class time explores topics in greater depth and creates meaningful learning opportunities, while educational technologies such as online videos are used to 'deliver content' outside of the classroom. In a flipped classroom, 'content delivery' may take a variety of forms such as videos, docs and PowerPoints. That is to say, the teacher has to be skillful in applying some software to make and edit short videos. It has been shown that the ideal length of the video lesson to be is eight to twelve minutes. Of course, an online platform has to be built by the school authority so that it is easier for both teachers and students to have an access to the learning resources.

There are features of the Flipped Classroom approach. First of all, it is apparent that a variety of learning resources (i.e. oral, visual, listening, hands on, problem solving, etc.) are available online so that it allows the students more time and space to learn all by themselves before entering the traditional classroom setting. In addition, rather than learning in a traditional classroom setting where the students are only the passive listeners and followers to the teaching content, Flipped Classroom place much value on application approach, by which the students are assigned to do some hands-on or problem solving activities designed by the teacher. Moreover, with the extremely convenient accessibility of Flipped Classroom learning resources as well as the internet-based social media platform such as Wechat, not only can the students have the foundational information of the course, but also do student-student and student-teacher interactions. What's more, a student-centered teaching model is highly valued for Flipped Classroom. Under the guidance of this principle, the students are encouraged to understand the underlying rationale behind the information provided to them. Students must undertake the responsibilities given to them in learning, as their personal work and contribution will be reflected in the grade that they receive at the end of the course. This will, in turn, make them better prepared for future, more difficult courses. Therefore, all the above ensure that the students achieve an overall success in obtaining a proper, effective education while avoiding the overarching mode of “cramming” for exams.

\section{CONCEIVE, DESIGN AND IMPLEMENTATION OF ENGLISH TEACHING Mode Based on PROJEct ANd WorkPlace APPLICATION}

\section{A. Conceive and Design of Teaching}

Firstly, the research object and teaching content are determined. Class A of Business English major is taken as the research object, and the whole class is divided into several project groups according to the scale of 4-6 students each. Take "English for Careers I" as the teaching content. Then, in the stage of project conceive and design the teacher maps the theme of each unit with the key points and skills involved and transforms the implementation details of each level project into electronic program instructions. The instructions specify the details of project implementation, including project name, labor of team member, project schedule, project coverage, expected objectives, project reporting and evaluation criteria, etc. The design of all the above projects is closely related to the students' career applications. For example, the three-level project we designed is the product launch, which includes the determination of the company's products, the conception and design of advertising trailer, and manuscript writing of product launch. In the practice of the previous level 4 or level 5 projects, the students mentioned above have fully mastered their work flow. Therefore, it is not difficult to see from this example that product launch is likely to be experienced by students majoring in business English in the future workplace, and it is inseparable from students' ability to apply in the workplace.

\section{B. Implementation of Teaching}

In the process of project implementation at all levels, the students need to first complete knowledge input and internalization through classroom teaching, and then accomplish projects at all levels through cooperative learning in groups and strive for excellent performance in terms of project evaluation.[3] The score will be included in the formative assessment. Therefore, in the process of project implementation, there is a competition between groups, which urges every student to participate with a serious attitude. Otherwise, the whole group will suffer a loss because of one particular team member's negative performance. Therefore, the interest between team members is binding, which to a certain extent guarantees the effect of project-based teaching.

In the implementation stage of project-based teaching, the teacher should specify the course orientation to the students at the first class in order to guide and encourage them to seriously treat each project designed in the course. In addition to completing theoretical teaching in each unit, a teacher's role is to be a mentor and advisor to assist and guide students to complete projects at all levels, to provide them with professional opinions or suggestions, and to respect and encourage their creative ideas. However, this does not mean that teachers replace students to complete the project. Each group should exert collective wisdom and strength to independently complete design and implementation of the project. When planning their own projects, students can use all means to turn their brainchild into practice. For example, a site on campus could be built into a business meeting room, where a scene of a regular business meeting could be presented. In addition, the forms of project reports can also be diversified. You can also choose to make your own micro-video after class and play it in class.

In the meantime, the flipped classroom method of teaching was also applied and integrated into the stage. During this period, online resources for pre-class and post-class learning, such as the background knowledge of the course, videos, the oral or writing tasks, and the analytical questions to be discussed in class, were provided. These resources come in various forms (i.e. oral, audio, visual, hands on, problem solving, etc.). In addition, a study-guide for every single learning process was also provided so that the students could come prepared to class. While in the traditional classroom setting, the students' job is to exhibit their pre-class learning 
achievement and put forward the puzzles they encountered and the teacher's job is to monitor the real-time progress of students' learning, give advices or responses to their puzzles and evaluate their learning outcome. Only in this way can it be guaranteed that the students complete the project or other learning tasks in comparatively high quality and the learning outcome be delivered on schedule.

\section{Evaluation of Teaching}

Evaluation of teaching is the final stage of the whole project implementation, which mainly involves the report and display of each project team. Teachers should help students clarify the language knowledge and language rules that they should master in the simulated workplace. When making presentation, each group adopts the form of student self-assessment, group mutual assessment and teacher comment. The scoring criteria for project evaluation have been established in the overall design stage of the project and are reflected in the project instruction. There are two main dimensions of evaluation, one is the overall evaluation of the whole project activity results, and the other is the individual evaluation of students' performance in the whole project completion process. After each group completes the project report and presentation, the teacher shall first guide the students to find the existing problems and solutions by themselves. At the same time, the teacher shall put forward his personal opinions and discuss with the students to reflect and summarize in a more comprehensive way. In this way, the abstract language knowledge is turned into a tool that can be applied to complete a specific task, which not only stimulates students' interest in learning, but also yields better teaching results.

\section{RESEARCH RESULTS}

\section{A. Questionnaire}

Before and after the implementation of project, we conducted a questionnaire survey on class A of Business English. The survey before implementation is the most powerful basis for the project-based teaching design and implementation, and the survey after is to test whether the research has a positive impact on students' learning attitude and interest, language ability and professional competence. In this survey, a total of 85 valid questionnaires were collected. The questions in the questionnaires mainly covered three aspects: Learning Motivation, Language Application Ability and Professional Competence. "Learning Motivation" includes Self-potential Display and Sense of Achievement, Useful and Pragmatic, Interesting and Moderately Difficult, Options and Autonomy of Learning, Diversified Evaluation and Harvest; "Language application ability" includes Improvement of Vocabulary Learning Ability, Enhancement of Reading Ability, Improvement of Oral Expression, and Enhancement of Applied Writing; "Professional Competence" includes Improvement of Teamwork, Creativity and Coordination, Ability of Problem Solving, Workplace Experience and the improvement of Professional English Application.

\section{B. Data Analysis}

This article only analyzes the survey results after the completion of the project.
First, the original data were tested for reliability, and the results are shown in TABLE I. Generally, Cronbach's Alpha coefficient is above 0.6 , which is considered to be of high credibility. As can be seen from TABLE I, the value of alpha is 0.734 , indicating that the survey has good reliability.

TABLE I. RELIABLE STATISTICS

\begin{tabular}{|l|l|l|}
\hline Cronbach's Alpha & $\begin{array}{l}\text { Cronbach's Alpha } \\
\text { based on standardized terms }\end{array}$ & The number of items \\
\hline 0.734 & 0.741 & 17 \\
\hline
\end{tabular}

Second, the test results of the three statistics constructed by means of equal weights are shown in TABLE II below.

As can be seen from the data in TABLE II, the probability that the average value of learning motivation, language application ability and professional competence is not less than .5 (that is, not less than most of the cases) reaches 0.637 , 0.658 and 0.512 respectively (the significance level of this result is $\alpha=0.05)$. From the perspective of statistical significance, this teaching mode and study has a positive role in promoting students' learning motivation, language application ability and professional competence, which also indicates that this teaching mode has been recognized and accepted by most students.

TABLE II. STATISTICS OF INDIVIDUAL SAMPLES

\begin{tabular}{|c|c|c|c|c|}
\hline & $\mathrm{N}$ & Mean & $\begin{array}{c}\text { Standard } \\
\text { Deviation }\end{array}$ & $\begin{array}{c}\text { Standard error of } \\
\text { the mean }\end{array}$ \\
\hline $\begin{array}{c}\text { Learning } \\
\text { Motivation }\end{array}$ & 85 & 6.3766 & 0.39002 & 0.04236 \\
\hline $\begin{array}{c}\text { Language } \\
\text { Application } \\
\text { Ability }\end{array}$ & 85 & 6.5828 & 0.38275 & 0.04167 \\
\hline $\begin{array}{c}\text { Professional } \\
\text { Competence }\end{array}$ & 85 & 5.1200 & 0.38083 & 0.04166 \\
\hline
\end{tabular}

\section{CONCLUSIONS}

At the teacher's level, it is not only feasible to break through the inherent traditional teaching methods and integrate the project teaching concept based on workplace with the Flipped Classroom, but also improve the teaching efficiency by carrying out project teaching according to different majors and workplaces. From the perspective of teaching mode, it breaks the traditional teacher-centered language input teaching mode, emphasizes student-student and teacher-student interaction and cooperative learning, and makes students become the subject of learning, the planner and practitioner of projects, and drives students' learning interest and motivation. From the perspective of teaching objectives, the new teaching mode allows the students a chance to apply the learned language knowledge and skills into the simulated workplace and also a chance to form a habit of autonomous learning and cooperative learning. From the perspective of teaching content, according to different professional skills required by different majors, the project design integrates the cultivation of both professional ability and skills, rather than that of either language knowledge or skills. On the other hand, the learning resources in various forms are all based on stimulating the students' learning interests and motives and cultivating their professional skills, so it is self-apparent that the learning resources provided are successful in realizing these goals. In the form of evaluation, 
multiple evaluations give students more space for growth and a sense of achievement. That means the teacher is no longer the only one who decides the final score of a student's performance in a semester. Each student is also entitled to being part of the evaluation and he or she also has a say in decision-making. The students can vote and score to decide whether the project done by a certain group is good or not. The score given by the students will be calculated and included into the scoring sheets.

At the students' level, students' learning enthusiasm and autonomy are developed, and their language application ability, professional ability and professional quality are also improved. The projects are created in the almost real context, induce the real language use, and make learning more practical and useful. Under the atmosphere of challenge and cooperation, students' own potential can be developed and most of them can feel the sense of achievement brought by project learning.
At the school level, TOPCARES-CDIO and OBE teaching mode is further implemented, English teaching reform is deepened, basic courses are guided to serve professional courses, quality of talent training is improved, seamless connection between English language skills and professional competence is realized, and competitiveness of graduates is improved.

\section{REFERENCES}

[1] Chen Wenjie, Ren Lijun, CDIO-based Project Teaching Reform of Singapore Polytechnic [J]. Chinese Vocational and Technical Education, 2009, (35).

[2] Wen Tao, Exploration and Construction of Integrated TOPCARES-CDIO Talent Training Mode [J]. China Higher Education, 2011, (7).

[3] Gao Yan, Research on the Application of Project Learning in College English Teaching [J]. Foreign Language World, 2010, (6):42-48, 56. 